\title{
Reproductive and Developmental Toxicity Screening Test of Ethyl Hydrogen Adipate in Rats
}

\author{
Chunja Nam ${ }^{1}$, Jae-Sik Hwang ${ }^{1}$, Kyoung-Goo Han ${ }^{1}$, Eunhye Jo ${ }^{2}$, Sun-kyoung Yoo ${ }^{2}$, \\ Ig-Chun Eom ${ }^{2}$ and Jong-Koo Kang ${ }^{3}$ \\ ${ }^{1}$ Biotoxtech Co., Ltd., Cheongju, Korea \\ ${ }^{2}$ Environmental Health Research Department, National Institute of Environmental Research, Incheon, Korea \\ ${ }^{3}$ Department of Laboratory Animal Medicine, College of Veterinary Medicine, Chungbuk National University, Cheongju, Korea
}

(Received November 18, 2015; Revised August 18, 2016; Accepted August 30, 2016)

\begin{abstract}
This study aimed to evaluate the potential toxicity and safety of ethyl hydrogen adipate (EHA) by determining its effect on the reproductive function and development of Sprague-Dawley (SD) rats at dose levels of 0 (control), 200, 400, and $800 \mathrm{mg} / \mathrm{kg} /$ day. One male and five females of the $800 \mathrm{mg} / \mathrm{kg} /$ day died. Body weight loss was observed in the males of the $800 \mathrm{mg} / \mathrm{kg} /$ day and in females of the 400 and $800 \mathrm{mg} /$ $\mathrm{kg} /$ day. In addition, mating indices decreased and pre-implantation loss rates increased in parental animals of the 400 and $800 \mathrm{mg} / \mathrm{kg} /$ day. The gestation index decreased in the male and female rats of the $800 \mathrm{mg} /$ $\mathrm{kg} /$ day. Moreover, the body weight of the pups from the $800 \mathrm{mg} / \mathrm{kg} /$ day group decreased on post-parturition day 4. These results indicated that the no-observed-adverse-effect level of EHA for parental males and females was $400 \mathrm{mg} / \mathrm{kg} / \mathrm{day}$ and $200 \mathrm{mg} / \mathrm{kg} /$ day, respectively, and that for pups was $400 \mathrm{mg} / \mathrm{kg} / \mathrm{day}$.
\end{abstract}

Key words: Ethyl hydrogen adipate, Reproductive and development toxicity, Screening test, Rat

\section{INTRODUCTION}

Ethyl hydrogen adipate (EHA) has many applications, including in organic synthesis and as pharmaceutical intermediate and solvent (1). EHA is used in synthetic resins, oxidizing agents, adhesive and additives of fuel, pigment, paint and ink. In the Republic of Korea, the production and use volumes of EHA were 28 and 52 tons in 2010 (2).

Information on the toxicity of this chemical is limited; therefore, the Organisation for Economic Co-operation and Development (OECD) cooperative chemical assessment program (CoCAP) conducted toxicity studies on EHA. In this program, an acute toxicity test, repeated dose 28-day oral toxicity study, skin irritation/corrosion test, eye irritation test, bacterial reverse mutation test, and in vitro mammalian chromosome aberration test were performed in

Correspondence to: Jong-Koo Kang, Department of Laboratory Animal Medicine, College of Veterinary Medicine, Chungbuk National University, 1 Chungdae-ro, Seowon-gu, Cheongju, Chungbuk 28644, Korea

E-mail: jkkang@cbu.ac.kr

This is an Open-Access article distributed under the terms of the Creative Commons Attribution Non-Commercial License (http:// creativecommons.org/licenses/by-nc/3.0) which permits unrestricted non-commercial use, distribution, and reproduction in any medium, provided the original work is properly cited. accordance with the OECD guidelines. The results of these tests suggested that (data not published) the oral $\mathrm{LD}_{50}$ for EHA was over $2,000 \mathrm{mg} / \mathrm{kg}$ for rats (2). In the repeated dose 28-day oral toxicity study with rats at doses of 0,200 , 400 , and $800 \mathrm{mg} / \mathrm{kg} /$ day, the no-observed-adverse-effect level was considered to be $200 \mathrm{mg} / \mathrm{kg} /$ day since hyperkeratosis, epithelial hyperplasia, ulcer, and submucosal inflammation occurred in the forestomach after the administration of 400 and $800 \mathrm{mg} / \mathrm{kg} /$ day EHA (2). EHA caused eye irritation, but not skin irritation. It showed no mutagenicity in the bacterial reverse mutation test and no potential chromosome aberrations in the in vitro chromosome aberration test in Chinese hamster lung cells (2).

However, no information is available on the reproductive and developmental toxicity of EHA. In this study, we conducted reproductive and developmental toxicity screening test of EHA in rats via the oral route to maximize system exposure in accordance with OECD Guideline 421 (3). The experimental design included examination of gonadal function, mating, conception, and parturition.

\section{MATERIALS AND METHODS}

All procedures were performed in accordance with the OECD Guideline for Testing of Chemicals, 421, Reproduction/Developmental Toxicity Screening Test (Adopted: July 


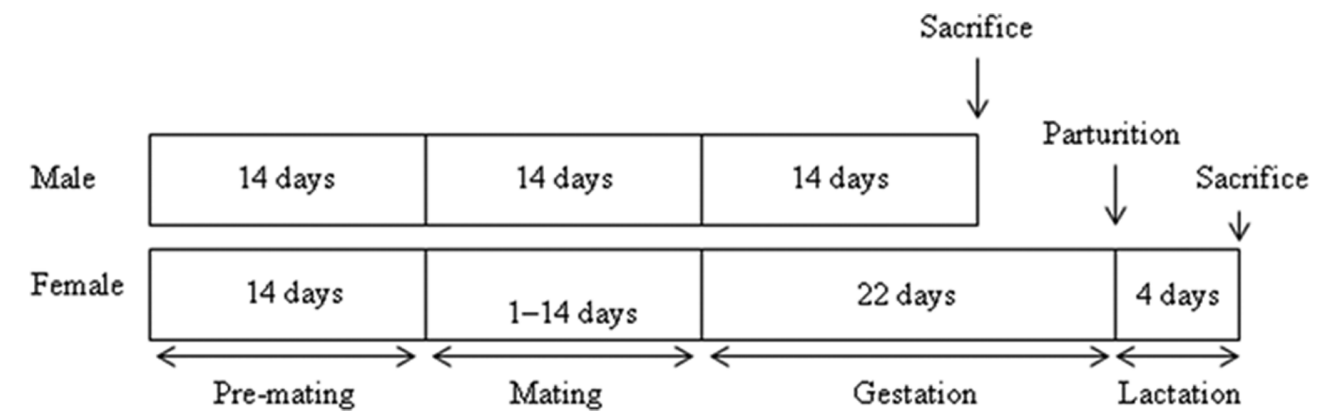

Fig. 1. Schematic of the study design.

27, 1995). The study was conducted in accordance with the Good Laboratory Practice (GLP) Regulation for Toxic Chemical Control Act (No.: 2013-1) issued by the Korean National Institute of Environmental Research, Korea (Jan 9, 2013), and the Principles of Good Laboratory Practice issued by the OECD (4).

Test substance and dose preparation. EHA (CAS No.: 626-86-8) was purchased from Sigma-Aldrich (MO, USA) EHA is a white solid, and its melting point, density, and molecular weight are $28 \sim 29^{\circ} \mathrm{C}, 0.98 \mathrm{~g} / \mathrm{mL}$ (at $25^{\circ} \mathrm{C}$ ), and 174.19 (5). The EHA (Lot No.: S09682V) used in this study was $97.4 \%$ pure and was maintained at room temperature. It was suspended in corn oil (Sigma-Aldrich), and the dosing formulations were prepared daily without analyses for homogeneity and stability.

Experimental animals and housing conditions. Specific pathogen-free Sprague-Dawley (Crl:CD (SD)) rats were used in this study. SD rats are commonly used in general and reproductive toxicity studies and have a large historical control database. For the study, 9-week-old males and 8-weekold females were purchased from ORIENTBIO INC. (Seongnam, Korea) and acclimated for 2 weeks before drug administration. The animals were randomly allocated to one control group and three treatment groups, each consisting of 12 males and 12 females.

The animals were housed in a GLP facility with controlled temperature $\left(22 \pm 3^{\circ} \mathrm{C}\right)$, humidity $(30 \sim 70 \%)$, ventilation (10 15 times/hr), light (12:12 hr, light : dark cycle), and illumination (150 300 lux). Feed (pelleted rodent chow; Harlan Laboratories, Inc., IN, USA) and sterilized tap water were provided ad libitum. The rats were housed individually in stainless steel cages, except for mating and postpartum periods. From the late stage of pregnancy to the day the animals were killed, individual dams and/or litters were reared using wood chips as bedding (SANI-CHIPS; Harlan Laboratories, Inc., IN, USA) for parturition and lactation.

This study was reviewed and approved by the Institutional Animal Care and Use Committees (IACUC) based on the Animal Protection Act (Approval No.: 130829).
Dose administration. An individual dose was calculated for each animal on the basis of the most recently recorded body weight data at a dose volume of $5 \mathrm{~mL} / \mathrm{kg}$. Rats were dosed once daily by gastric intubation with EHA at a dose of $0,200,400$, or $800 \mathrm{mg} / \mathrm{kg} /$ day. Control rats were administered corn oil. The treatment dose was determined based on a previous 1-week repeated oral toxicity study. The body weight gain and food consumption of males administered $1,000 \mathrm{mg} / \mathrm{kg} /$ day EHA decreased during the 1 -week treatment period (data not shown). Males were dosed once daily for 42 days from 2 weeks before mating to 2 weeks after mating. Females were dosed once daily from 2 weeks before mating to 4 days after delivery. Further, females showing no evidence of copulation or those in which mating was confirmed, but no signs of pregnancy were noted, were dosed once daily up to 26 days after the last day of the mating period. In females, dosing solutions were administered for 41 54 days (Fig. 1).

Observations. All animals were observed daily for clinical signs throughout the study. Body weights of males were recorded on the first day of dosing (before dosing), once a week throughout the dosing period and on the day of necropsy. Body weights of females were recorded on the first day of dosing (before dosing), once a week throughout the dosing period (except mating period), on days $0,7,14$, and 20 of gestation, on days 0 and 4 of postpartum, and on the day of necropsy. Food consumptions were measured once a week during the dosing period for males, and once a week and on days 0 and 3 of postpartum for females (except the mating period).

Male and female rats were mated at a ratio of $1: 1$ until copulation occurred or 2 weeks had elapsed. All females were examined for the presence of a vaginal plug (or a vaginal smear) twice a day (morning and afternoon) for confirmation of mating. The day of positive confirmation was defined as day 0 of gestation.

Body weights of pups were recorded on days 0 and 4 of postpartum. On postpartum day 0 , each litter was examined for number and sex of pups and the presence of gross abnormalities. Pups were euthanized with $\mathrm{CO}_{2}$ after the completion of external examination on postpartum day 4 . 
Male animals were necropsied at week 2 after the mating period, and female animals were necropsied on day 5 of postpartum by exsanguination under isoflurane anesthesia after they were fasted for $18 \mathrm{hr}$. Females without confirmed mating were necropsied on day 27 after the mating period. At necropsy, the organs and tissues with gross abnormalities were harvested in $10 \%$ neutral buffered formalin except for the testes and epididymides, which were fixed in Bouin's solution, and then stored in 10\% neutral buffered formalin. The ovaries, testes, epididymides and other organs and tissues with gross abnormalities were subjected to histopathological examination.

Statistical analysis. The data were statistically analyzed using SAS program (Version 9.3; SAS Institute Inc., Cary, NC, USA). Body weights, food consumption, mating period, gestation period, pre- and post-implantation loss rates, live birth index, viability index on postpartum days 0 and 4 , and organ weight data were analyzed using Bartlett test for homogeneity of variance (significance level: 0.05 ). One-way analysis of variance (ANOVA) test was used for homogeneity; if the values were significant (significance level: 0.05), Dunnett's $t$-test was applied for multiple comparisons (significance level: 0.05 and 0.01 , two-tailed). Kruskal-Wallis test was used for heterogeneous data; if these data were significant (significance level: 0.05), Steel's test was applied for multiple comparisons (significance level: 0.05 and 0.01 , two-tailed). Mating, male and female fertility index data, and data associated with gestation were analyzed using Fischer's exact text (significance levels: 0.05 and 0.01 ).

\section{RESULTS AND DISCUSSION}

Clinical signs. The clinical signs in rats administered EHA are shown in Table 1. One male rat of the $800 \mathrm{mg} / \mathrm{kg} /$ day group died on dosing day 26 . The animal exhibited several clinical signs such as salivation, irregular respiration, nasal hemorrhage, mucous stool, and diarrhea or abdominal distention from dosing day 19. Five female rats of the $800 \mathrm{mg} / \mathrm{kg} /$ day group died on day 4, day 11 (no-mating), days 13 and 18 after the mating period, and on mating day 5 . These animals had irregular respiration (audible respiration), mucous stool, diarrhea, staining around the mouth, dirty nose, soiled perineal region, or hypothermia.

One female rat of the $800 \mathrm{mg} / \mathrm{kg} /$ day group had irregular respiration after parturition. One female of the $400 \mathrm{mg} / \mathrm{kg} /$ day group had mucous stool and irregular respiration from day 15 after the mating period.

Two female rats of the $400 \mathrm{mg} / \mathrm{kg} /$ day group had irregular respiration (audible respiration), deep respiration, staining around the mouth, dirty nose, or nasal hemorrhage; one of the females died, and the other one was moribund.

Owing to the nature of the test substance, gavage-related
Table 1. Summary of clinical signs

\begin{tabular}{|c|c|c|c|c|c|}
\hline \multirow{3}{*}{ Signs } & Group & G1 & G2 & G3 & G4 \\
\hline & Dose (mg/kg/day) & 0 & 200 & 400 & 800 \\
\hline & No. of animals & 12 & 12 & 12 & 12 \\
\hline \multicolumn{6}{|c|}{ Sex: male } \\
\hline \multicolumn{2}{|c|}{ Abdominal distention } & & & & 1 \\
\hline \multicolumn{2}{|c|}{ Diarrhea } & & & & 1 \\
\hline \multicolumn{2}{|c|}{ Irregular respiration } & & & & 1 \\
\hline \multicolumn{2}{|c|}{ Mucous stool } & & & & 1 \\
\hline \multicolumn{2}{|c|}{ Nasal hemorrhage } & & & & 1 \\
\hline \multicolumn{2}{|c|}{ Salivation } & & & & 12 \\
\hline \multicolumn{2}{|c|}{ Death } & & & & 1 \\
\hline \multicolumn{6}{|c|}{ Sex: female } \\
\hline \multicolumn{6}{|c|}{ Premating and mating period } \\
\hline \multicolumn{2}{|c|}{ Abdominal distention } & & & & 1 \\
\hline \multicolumn{2}{|c|}{ Deep respiration } & & & 1 & \\
\hline \multicolumn{2}{|c|}{ Dirty nose } & & & 1 & 1 \\
\hline \multicolumn{2}{|c|}{ Dyspnea } & & & 2 & \\
\hline \multicolumn{2}{|c|}{ Hypothermia } & & & & 1 \\
\hline \multicolumn{2}{|c|}{ Irregular respiration } & & & 2 & 2 \\
\hline \multicolumn{2}{|c|}{ Mucous stool } & & & & 2 \\
\hline \multicolumn{2}{|c|}{ Nasal hemorrhage } & & & 1 & 1 \\
\hline \multicolumn{2}{|c|}{ Salivation } & & & & 12 \\
\hline \multicolumn{2}{|c|}{ Soiled perineal region } & & & & 1 \\
\hline \multicolumn{2}{|c|}{ Staining around mouth } & & & & 2 \\
\hline \multicolumn{2}{|c|}{ Moribund } & & & 1 & \\
\hline \multicolumn{2}{|c|}{ Death } & & & 1 & 1 \\
\hline \multicolumn{6}{|c|}{ Gestation period } \\
\hline \multicolumn{2}{|c|}{ Abdominal distention } & & & & 1 \\
\hline & & & & & 1 \\
\hline & & & & & 1 \\
\hline & respiration & & & 1 & 4 \\
\hline & tool & & & 1 & \\
\hline & & & & & 5 \\
\hline & around mouth & & & & 1 \\
\hline & & & & & 4 \\
\hline Post & period & & & & \\
\hline & respiration & & 1 & & 1 \\
\hline & & & & & 1 \\
\hline & leeding & & 1 & & \\
\hline & & & 1 & & \\
\hline
\end{tabular}

reflux is known to occur more often than expected, and is mediated by increased viscosity, irritancy, and/or stability problems (e.g., high lipophilicity and acids) (6); thus, the death might be attributed to the gavage-related reflux considering the clinical signs and time of death.

One female rat of the $200 \mathrm{mg} / \mathrm{kg} /$ day group gave birth to a stillborn with clinical signs such as irregular respiration and vaginal bleeding. The female found dead on the day after parturition had two dead fetuses in the uterus. Because no clinical signs were observed before parturition, the death was not considered to be associated with the administration of the test substance, but was considered to be an incidental finding owing to dystocia. 


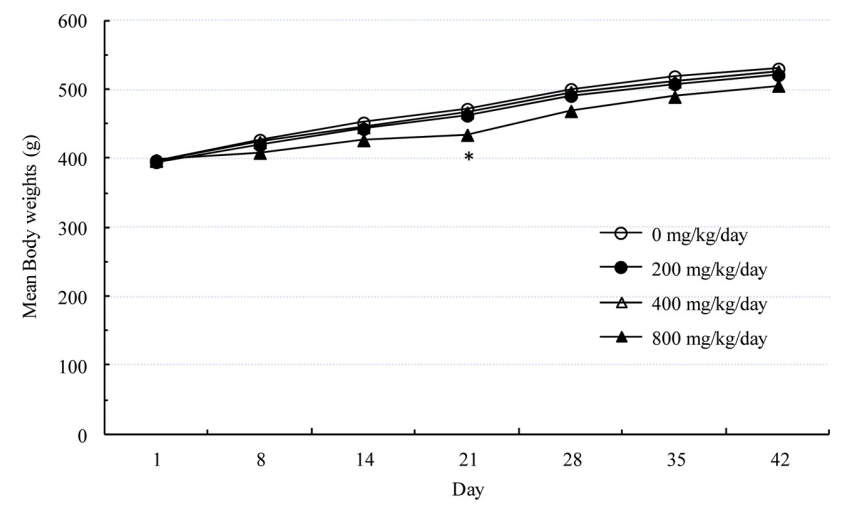

Fig. 2. Mean body weights of male rats. *Significantly different from the control, $p \leq 0.05$.

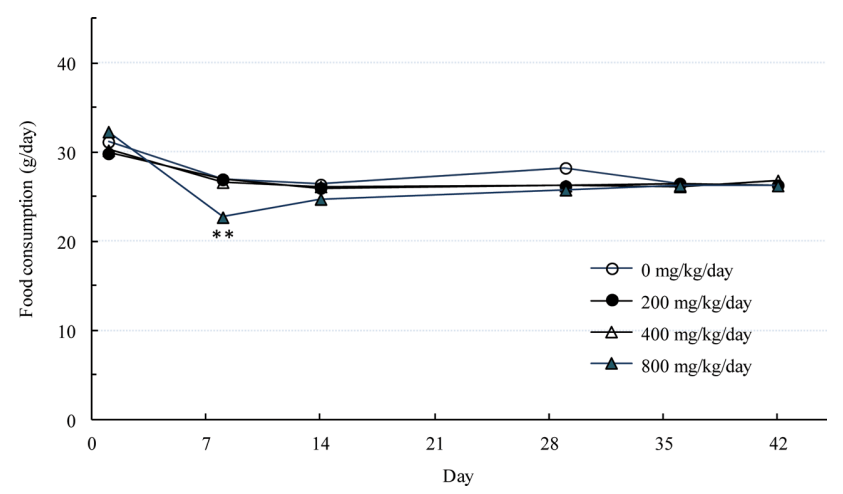

Fig. 4. Mean food consumptions in male rats. ${ }^{* *}$ Significantly different from the control, $p \leq 0.01$.

Body weight and food consumption. The body weight changes in rats administered EHA are shown in Figs. 2 and 3. Body weight of male rats of the $800 \mathrm{mg} / \mathrm{kg} /$ day group

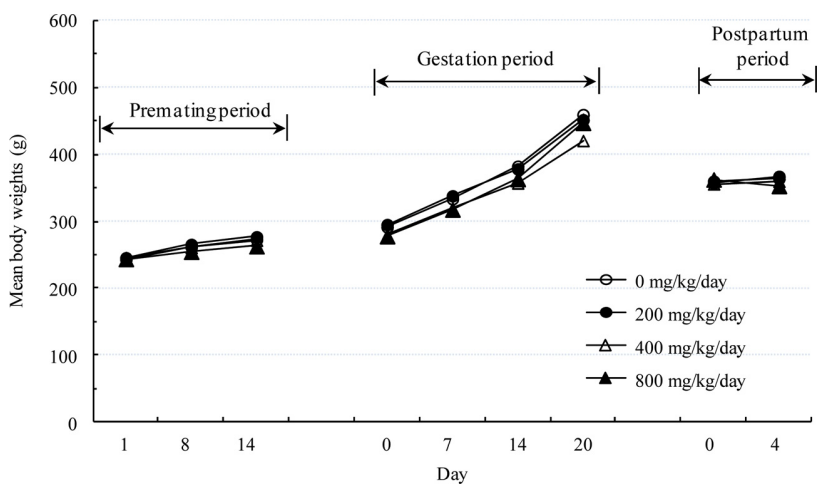

Fig. 3. Mean body weights of female rats.

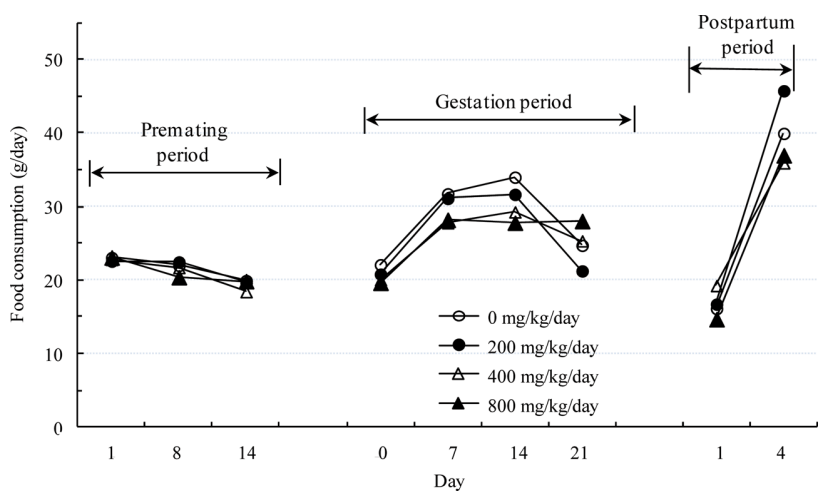

Fig. 5. Mean food consumptions in female rats.

decreased significantly on dosing day 21 compared to that of the control group $(p<0.05)$. For the remaining dosing periods, the body weights of rats of this dosing group showed a decreasing tendency (approximately 4.4 8.0\% lower than those of the controls). Although the body weight

Table 2. Summary of Mating and gestation results

\begin{tabular}{|c|c|c|c|c|c|c|c|c|c|}
\hline $\begin{array}{l}\text { Group/ } \\
\text { Dose } \\
\text { (mg/kg/day) }\end{array}$ & $\begin{array}{l}\text { No. of females } \\
\text { placed with } \\
\text { males }\end{array}$ & $\begin{array}{c}\text { No. of } \\
\text { females } \\
\text { mated }\end{array}$ & $\begin{array}{l}\text { No. of } \\
\text { females } \\
\text { pregnant }\end{array}$ & $\begin{array}{c}\text { Mating } \\
\text { index } \\
(\%)\end{array}$ & $\begin{array}{c}\text { Male } \\
\text { fertility } \\
\text { index (\%) }\end{array}$ & $\begin{array}{c}\text { Female } \\
\text { fertility } \\
\text { index (\%) }\end{array}$ & & $\begin{array}{c}\text { Mating } \\
\text { period } \\
\text { (day) }\end{array}$ & $\begin{array}{l}\text { Gestation } \\
\text { period (day) }\end{array}$ \\
\hline G1 & 12 & 12 & 12 & 100.0 & 100.0 & 100.0 & Mean & 4.8 & 22.4 \\
\hline \multirow[t]{2}{*}{0} & & & & & & & S.D. & 4.3 & 0.5 \\
\hline & & & & & & & $\mathrm{N}$ & 12.0 & 12.0 \\
\hline $\mathrm{G} 2$ & 12 & 12 & 12 & 100.0 & 100.0 & 100.0 & Mean & 6.3 & 22.2 \\
\hline \multirow[t]{2}{*}{200} & & & & & & & S.D. & 4.8 & 0.6 \\
\hline & & & & & & & $\mathrm{N}$ & 12.0 & 11.0 \\
\hline G3 & 10 & 8 & 8 & 80.0 & 100.0 & 100.0 & Mean & 4.3 & 22.6 \\
\hline \multirow[t]{2}{*}{400} & & & & & & & S.D. & 3.9 & 0.5 \\
\hline & & & & & & & $\mathrm{N}$ & 8.0 & 7.0 \\
\hline G4 & 11 & 9 & 6 & 81.8 & 75.0 & 75.0 & Mean & 4.4 & 22.3 \\
\hline \multirow[t]{2}{*}{800} & & & & & & & S.D. & 4.2 & 0.5 \\
\hline & & & & & & & $\mathrm{N}$ & 9.0 & 4.0 \\
\hline
\end{tabular}

Mating index $(\%)=($ No. of females mated/no. of females placed with males $) \times 100$.

Male fertility index $(\%)=($ No. of males impregnating a female/no. of males with confirmed mating $) \times 100$.

Female fertility index $(\%)=($ No. of females pregnant $/$ no. of females with confirmed mating $) \times 100$. 
Table 3. Summary of Delivery and pups data

\begin{tabular}{|c|c|c|c|c|c|c|c|c|c|c|c|c|c|c|c|c|c|c|c|c|}
\hline \multirow{3}{*}{\multicolumn{2}{|c|}{$\begin{array}{l}\text { Group/ } \\
\text { Dose } \\
(\mathrm{mg} / \mathrm{kg} / \text { day) }\end{array}$}} & \multirow{2}{*}{\multicolumn{2}{|c|}{$\begin{array}{c}\text { No. of } \\
\text { corpora } \\
\text { lutea }\end{array}$}} & \multirow{2}{*}{\multicolumn{2}{|c|}{$\begin{array}{l}\text { No. of } \\
\text { implantation }\end{array}$}} & \multirow{2}{*}{\multicolumn{2}{|c|}{$\begin{array}{l}\text { Implantation } \\
\text { loss rate (\%) }\end{array}$}} & \multirow{3}{*}{$\begin{array}{c}\text { Live } \\
\text { birth } \\
\text { index } \\
(\%)\end{array}$} & \multicolumn{5}{|c|}{ PND 0} & \multirow{2}{*}{\multicolumn{2}{|c|}{$\begin{array}{c}\text { PND } 4 \\
\text { No. of } \\
\text { live pups }\end{array}$}} & \multirow{2}{*}{\multicolumn{2}{|c|}{$\begin{array}{l}\text { Viability } \\
\text { index (\%) }\end{array}$}} & \multirow{3}{*}{$\begin{array}{c}\text { Sex } \\
\text { ratio } \\
\text { (male/ } \\
\text { female) }\end{array}$} & \multirow{3}{*}{$\begin{array}{c}\text { Gestation } \\
\text { index } \\
(\%)\end{array}$} & \multirow{3}{*}{$\begin{array}{c}\text { Delivery } \\
\text { (No. of } \\
\text { abnormality) }\end{array}$} \\
\hline & & & & & & & & & \multicolumn{3}{|c|}{$\begin{array}{c}\text { No. of } \\
\text { pups born }\end{array}$} & \multicolumn{2}{|c|}{$\begin{array}{c}\text { No. of } \\
\text { live pups }\end{array}$} & & & & & & & \\
\hline & & Left & Right & Left & Right & Pre- & Post- & & Live & Dead & Total & Male & Female & Male & Female & PND 0 & PND 4 & & & \\
\hline G1 & Mean & 8.8 & 8.8 & 7.3 & 7.5 & 16.7 & 8.3 & 91.7 & 13.3 & 0.6 & 13.9 & 7.3 & 6.0 & 7.3 & 5.8 & 96.6 & 97.7 & 12 & 100.0 & 0 \\
\hline 0 & S.D. & 2.1 & 2.5 & 2.2 & 2.4 & 8.3 & 12.5 & 12.5 & 3.7 & 2.0 & 3.7 & 2.7 & 1.7 & 2.8 & 1.6 & 11.9 & 4.5 & $88 / 72$ & & \\
\hline & $\mathrm{N}$ & 12 & 12 & 12 & 12 & 12 & 12 & 12 & 12 & 12 & 12 & 12 & 12 & 12 & 12 & 12 & 12 & 12 & & \\
\hline G2 & Mean & 8.6 & 8.4 & 7.1 & 7.5 & 15.2 & 17.6 & 82.4 & 13.1 & 1.5 & 14.4 & 7.5 & 6.9 & 7.4 & 6.7 & 100.0 & 98.0 & 1.1 & 83.3 & 1 \\
\hline 200 & S.D. & 2.4 & 2.6 & 3.6 & 3.3 & 25.9 & 28.0 & 28.0 & 4.9 & 5.1 & 2.4 & 2.1 & 2.6 & 2.1 & 2.5 & 0.0 & 3.3 & $75 / 69$ & & \\
\hline & $\mathrm{N}$ & 12 & 12 & 11 & 11 & 11 & 11 & 11 & 11 & 11 & 10 & 10 & 10 & 10 & 10 & 10 & 10 & 10 & & \\
\hline G3 & Mean & 7.0 & 8.0 & 5.1 & 6.9 & 27.5 & 22.1 & 89.0 & 12.6 & 0.0 & 12.6 & 5.6 & 7.0 & 5.6 & 6.6 & 100.0 & 97.7 & 0.8 & 87.5 & 0 \\
\hline 400 & S.D. & 2.5 & 3.8 & 2.7 & 4.5 & 25.1 & 35.9 & 18.7 & 6.6 & 0.0 & 6.6 & 2.9 & 3.8 & 2.9 & 3.5 & 0.0 & 4.3 & $39 / 49$ & & \\
\hline & $\mathrm{N}$ & 8 & 8 & 8 & 8 & 8 & 8 & 7 & 7 & 7 & 7 & 7 & 7 & 7 & 7 & 7 & 7 & 7 & & \\
\hline G4 & Mean & 9.7 & 9.7 & 7.7 & 7.7 & 20.7 & 0.0 & 100.0 & 14.3 & 0.0 & 14.3 & 6.8 & 7.5 & 6.5 & 7.0 & 100.0 & 94.3 & 0.9 & 66.7 & 0 \\
\hline 800 & S.D. & 2.3 & 3.8 & 2.0 & 3.1 & 8.3 & 0.0 & 0.0 & 3.3 & 0.0 & 3.3 & 1.7 & 2.4 & 1.9 & 2.0 & 0.0 & 4.2 & $27 / 30$ & & \\
\hline & $\mathrm{N}$ & 6 & 6 & 6 & 6 & 6 & 4 & 4 & 4 & 4 & 4 & 4 & 4 & 4 & 4 & 4 & 4 & 4 & & \\
\hline
\end{tabular}

Pre-imp. loss rate $(\%)=($ (No. of corpora lutea-no. of implantations $) /$ no. of corpora lutea $) \times 100$.

Post-imp. loss rate $(\%)=(($ No. of implantations-no. of live pups $) /$ no. of implantations $) \times 100$.

Live birth index $(\%)=($ No. of live pups on postnatal day $0 /$ no. of implantations $) \times 100$.

Viability index on PND $0(\%)=($ No. of pups born alive on PND 0/total no. of pups born) $\times 100$.

Viability index on PND $4(\%)=($ No. of pups surviving on PND 4/no. of pups born alive on PND 0$) \times 100$.

Gestation index $(\%)=($ No. of females with live pups $/$ no. of pregnant females $) \times 100$.

Sex ratio $=$ No. of live males pups/no. of live females pups (on postpartum Day 0 ). 


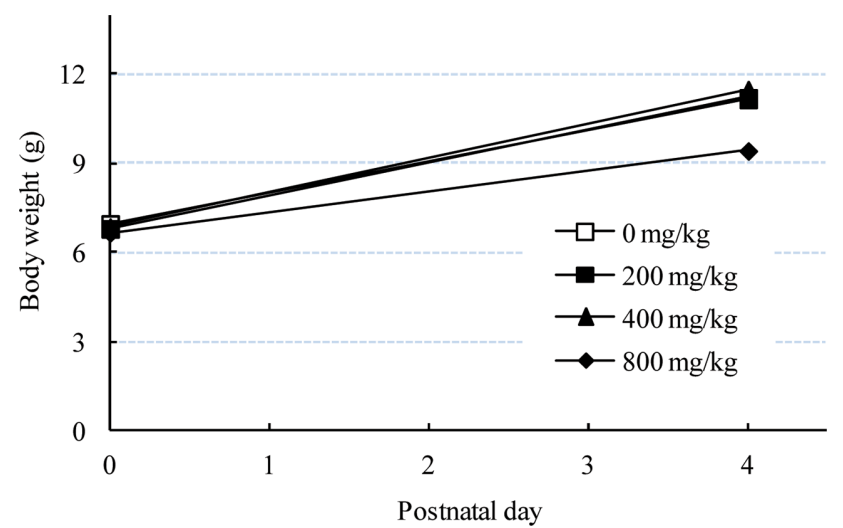

Fig. 6. Mean body weight of male pups.

in female rats of the 400 and $800 \mathrm{mg} / \mathrm{kg} /$ day groups did not decrease significantly, it tended to decrease during the gestation period (approximately 4.1 8.4\% lower than those of the controls).

The food consumption rates in rats administered EHA are shown in Figs. 4 and 5. Food consumption in male rats of the $800 \mathrm{mg} / \mathrm{kg} /$ day group decreased significantly on dosing day 8 compared to that of the control group $(p<0.01)$. However, there were no significant changes in food consumption during the other dosing periods.

Reproduction function and pups' examination. Table 2 shows the reproductive function of rats administered EHA. Mating indices of the 400 and $800 \mathrm{mg} / \mathrm{kg} /$ day groups and fertility index of the $800 \mathrm{mg} / \mathrm{kg} /$ day group decreased markedly compared to those of the control group. EHA had no effects on the mating and gestation period.

The developmental toxicity effects of EHA in rats are shown in Table 3. Pre-implantation loss rates in the 400 and $800 \mathrm{mg} / \mathrm{kg} /$ day groups increased and gestation index in the $800 \mathrm{mg} / \mathrm{kg} /$ day group decreased compared to those of the control group. Some adipic acid ethers have been shown to increase the resorption rates in studies conducted on embryonic-fetal toxicity (7). The increase in the post-implantation loss rate in the 200 and $400 \mathrm{mg} / \mathrm{kg} /$ day groups was considered to be incidental, because one maternal animal per group was pregnant with only one dead pup in the uterus; this might have increased the mean post-implantation loss rates. Although gestation indices in the 200 and $400 \mathrm{mg} / \mathrm{kg} /$ day groups were $83.3 \%$ (number of females with live pups: $10 / 12$ ) and $87.5 \%$ (number of females with live pups: 7/8), respectively, the index in the $400 \mathrm{mg} / \mathrm{kg} /$ day group was within the historical data range $(97.3 \pm 10.26 \%)$ (8). The decreased index in the $200 \mathrm{mg} / \mathrm{kg}$ /day group was not considered to be related to the test substance, because the change was less significant and the index was slightly lower than the historical data range.

The body weights of the F1 generation are shown in Figs.

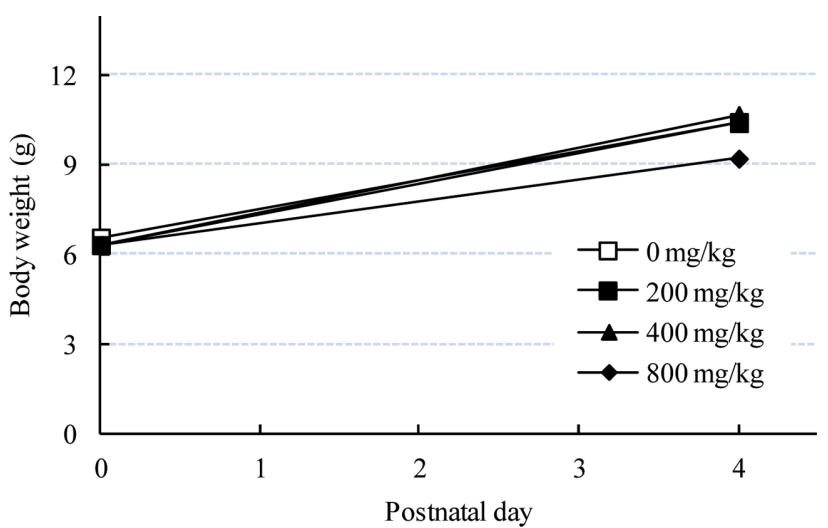

Fig. 7. Mean body weight of female pups.

6 and 7. There were no differences in the body weights of pups on postpartum day (PPD) 0 . However, the body weights of pups of the $800 \mathrm{mg} / \mathrm{kg} /$ day group on PPD 4 decreased by $15.5 \%$ in males and by $11.4 \%$ in females compared to those of the control group, although these were not statistically significant.

In all the test groups, there were no changes in the external morphology of the pups.

Necropsy. The necropsy findings in rats administered EHA are shown in Table 4. There were no abnormal findings in the testes and epididymides of males and ovaries of females in all the dosing groups. One dead male and five dead female rats of the $800 \mathrm{mg} / \mathrm{kg} /$ day group had prominent distention of the stomach and cecum and small spleen and thymus. Focal forestomach thickening was observed in the male rat. At the scheduled necropsy, the thymus of each female rat of the 400 and $800 \mathrm{mg} / \mathrm{kg} /$ day groups was found to be small.

Two dead fetuses were found in the right and left uterine horns of a female rat of the $400 \mathrm{mg} / \mathrm{kg} /$ day group that died on PPD 1. Enlargement of the spleen and adrenal gland, small thymus, and black or white focal lesions in the glandular stomach were observed in the female rat. In addition, one dead fetus was found in the uterus of each female showing no evidence of parturition in the 200 and $400 \mathrm{mg} /$ $\mathrm{kg} /$ day groups. These changes were considered to be incidental findings.

Organ weights. The organ weights of rats administered EHA are shown in Table 5. The weights of the testes and epididymides of males of the treated groups did not show any test substance-related changes compared to that of control groups.

Histopathology. The histopathological findings in rats administered EHA are shown in Table 6 . In the $800 \mathrm{mg} / \mathrm{kg} /$ day group, hyperkeratosis, squamous cell hyperplasia, and 
Table 4. Summary of necropsy findings

\begin{tabular}{|c|c|c|c|c|c|c|c|c|c|}
\hline \multirow[b]{2}{*}{ Organ/Findings } & \multicolumn{2}{|l|}{ Sex } & \multicolumn{3}{|c|}{ Male } & \multicolumn{4}{|c|}{ Female } \\
\hline & Group & G1 & G2 & G3 & G4 & G1 & G2 & G3 & G4 \\
\hline & Dose (mg/kg/day) & 0 & 200 & 400 & 800 & 0 & 200 & 400 & 800 \\
\hline \multicolumn{10}{|l|}{ Survived animals } \\
\hline & No. of examined & 12 & 12 & 12 & 11 & 12 & 11 & 10 & 7 \\
\hline & Remarkable findings & & & & & & 1 & 2 & 1 \\
\hline Thymus & - Small & & & & & & & 1 & 1 \\
\hline Uterus & - Presence, one dead fetus in lumen, left horn & & & & & & 1 & 1 & \\
\hline \multicolumn{10}{|l|}{ Dead animals } \\
\hline & No. of examined & & & & 1 & & 1 & 2 & 5 \\
\hline & Remarkable findings & & & & 1 & & 1 & & 5 \\
\hline Adrenal & - Enlargement, bilateral & & & & 1 & & 1 & & 1 \\
\hline Cecum & - Distension & & & & 1 & & & & 5 \\
\hline Spleen & - Enlargement & & & & & & 1 & & \\
\hline \multirow[t]{4}{*}{ Stomach } & - Distension & & & & 1 & & & & 5 \\
\hline & - Focus, black/white, many, glandular stomach & & & & & & 1 & & \\
\hline & - Focus, red, glandular stomach & & & & & & & & 1 \\
\hline & - Thickening, forestomach, focal & & & & 1 & & & & \\
\hline Thymus & - Small & & & & 1 & & 1 & & 5 \\
\hline Uterus & - Presence, two dead fetus in lumen, bilateral & & & & & & 1 & & \\
\hline
\end{tabular}

Table 5. Summary of absolute and relative organ weights (Sex: male)

\begin{tabular}{|c|c|c|c|c|c|c|c|c|c|c|}
\hline \multirow{2}{*}{$\begin{array}{l}\text { Group/ } \\
\text { Dose (mg/kg/day) }\end{array}$} & & \multirow{2}{*}{ B.W. } & \multicolumn{2}{|c|}{ Testes $(\mathrm{g})$} & \multicolumn{2}{|c|}{ Epididymides (g) } & \multicolumn{2}{|c|}{ Testes (g) } & \multicolumn{2}{|c|}{ Epididymides (g) } \\
\hline & & & Lt. & Rt. & Lt. & Rt. & Lt. & Rt. & Lt. & Rt. \\
\hline G1 & Mean & 511.1 & 1.79 & 1.78 & 0.73 & 0.76 & 0.35 & 0.35 & 0.15 & 0.15 \\
\hline \multirow[t]{2}{*}{0} & S.D. & 26.4 & 0.14 & 0.14 & 0.04 & 0.06 & 0.03 & 0.03 & 0.01 & 0.01 \\
\hline & $\mathrm{N}$ & 12 & 12 & 12 & 12 & 12 & 12 & 12 & 12 & 12 \\
\hline $\mathrm{G} 2$ & Mean & 499.2 & 1.71 & 1.73 & 0.71 & 0.73 & 0.35 & 0.35 & 0.14 & 0.15 \\
\hline \multirow[t]{2}{*}{200} & S.D. & 39.7 & 0.12 & 0.11 & 0.06 & 0.04 & 0.03 & 0.03 & 0.01 & 0.01 \\
\hline & $\mathrm{N}$ & 12 & 12 & 12 & 12 & 12 & 12 & 12 & 12 & 12 \\
\hline G3 & Mean & 506.1 & 1.75 & 1.76 & 0.72 & 0.75 & 0.35 & 0.35 & 0.14 & 0.15 \\
\hline \multirow[t]{2}{*}{400} & S.D. & 37.3 & 0.18 & 0.21 & 0.04 & 0.06 & 0.05 & 0.05 & 0.01 & 0.02 \\
\hline & $\mathrm{N}$ & 12 & 12 & 12 & 12 & 12 & 12 & 12 & 12 & 12 \\
\hline G4 & Mean & 482.3 & 1.79 & 1.80 & 0.72 & 0.74 & 0.37 & 0.38 & 0.15 & 0.15 \\
\hline \multirow[t]{2}{*}{800} & S.D. & 31.2 & 0.13 & 0.13 & 0.07 & 0.04 & 0.04 & 0.04 & 0.02 & 0.01 \\
\hline & $\mathrm{N}$ & 11 & 11 & 11 & 11 & 11 & 11 & 11 & 11 & 11 \\
\hline
\end{tabular}

ulcer in the forestomach were observed in one dead male rat that was found dead. Squamous cell hyperplasia in the forestomach and hemorrhage in the glandular stomach were also observed in one dead female rat of the $800 \mathrm{mg} / \mathrm{kg} /$ day group. The lesions of the forestomach might have been induced by intake of acids (9). Lymphoid atrophy of the thymus or spleen was observed in one dead male and five dead female rats of the $800 \mathrm{mg} / \mathrm{kg} /$ day group.

Because these animals exhibited several clinical signs such as body weight loss, irregular respiration, diarrhea, and abdominal distention, the lymphoid atrophy in the thymus and spleen was less likely to be caused by the toxicity induced by the test chemical. The change was probably secondary to the clinical signs and stress.
Distention of the stomach and cecum was observed in the animals found dead in the $800 \mathrm{mg} / \mathrm{kg} /$ day group. Histopathological changes could not be observed in several animals that had died owing to postmortem autolysis. Even in the remaining animals, histopathological changes associated with the distention were not observed.

Lymphoid atrophy in the thymus was observed in each female having correlated clinical signs in the 400 and 800 $\mathrm{mg} / \mathrm{kg} /$ day groups. It was also considered to be secondary to the clinical signs and stress.

Necrosis in the spleen, epithelial necrosis in the glandular stomach, and luteal necrosis in the ovary were observed in one dead female rat of the $200 \mathrm{mg} / \mathrm{kg} /$ day group. In addition, hemorrhage and inflammation were observed in the 
Table 6. Summary of histopathological findings

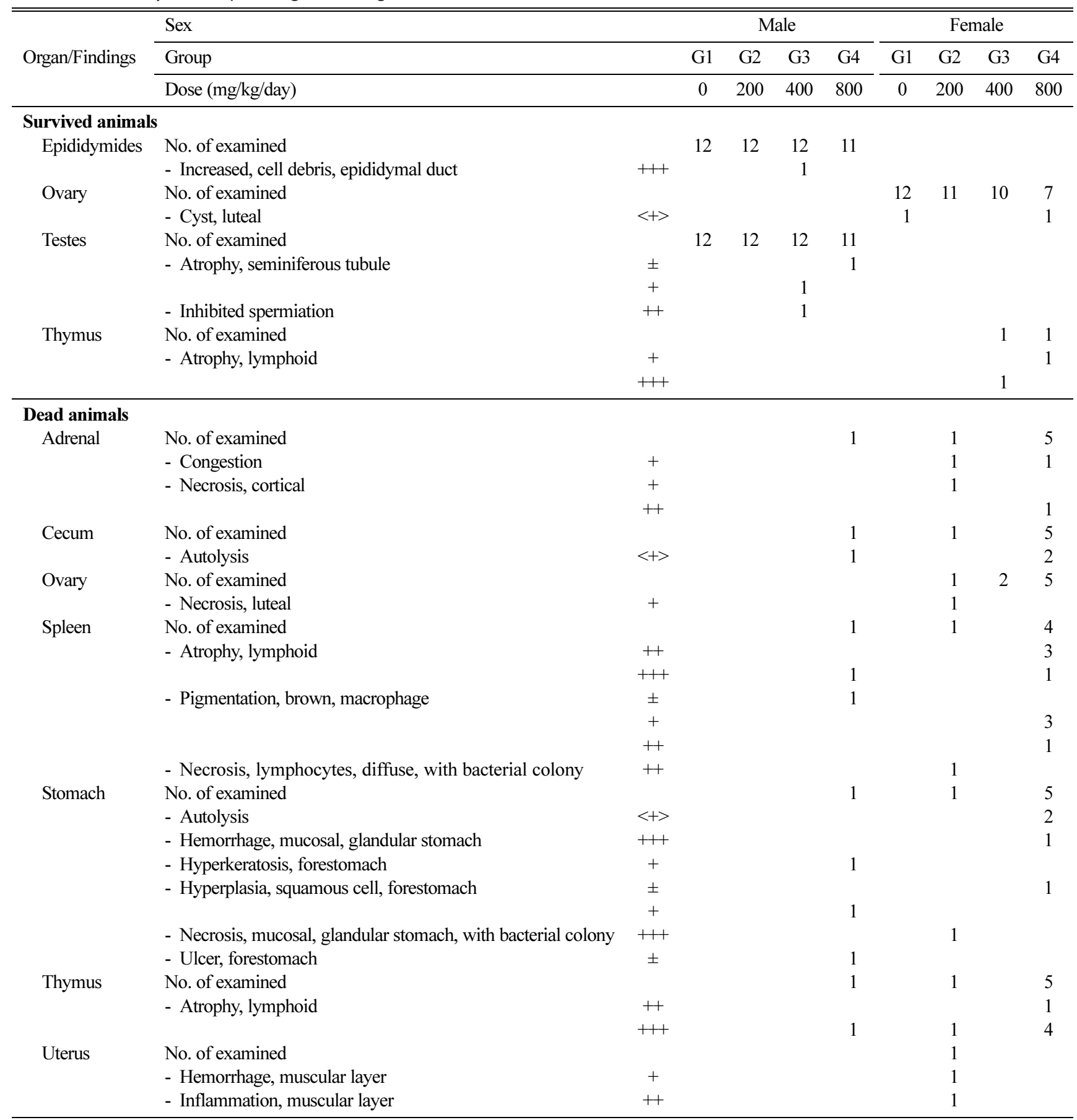

Grade; \pm : minimal, +: mild, ++: moderate, +++: marked. <+>: Presence in "presence or not" basis.

muscular layer of the uterus wherein dead fetuses were found. This was considered to be an incidental death due to dystocia.

Other sporadic changes were not considered to be related to the administration of the test substance.

Seminiferous tubule atrophy and inhibited spermiation in the testes and increased cell debris in the epididymal ducts of the epididymides were observed in one male rat of the $400 \mathrm{mg} / \mathrm{kg}$ /day group. However, the changes were considered to be congenital and were incidentally observed only once. Hemorrhage and inflammation were observed in the muscular layer of the uterus of the female with a dead fetus. Because the changes were caused by septicemia induced by dystocia, they were considered to be incidental findings. 
Other incidental findings were not considered to be related to the administration of the test substance.

In conclusion, it was concluded that no observed adverse effect level (NOAEL) for parental male animals was considered to be $400 \mathrm{mg} / \mathrm{kg} /$ day based on the mortality at 800 $\mathrm{mg} / \mathrm{kg}$. The NOAEL for parental female animals was considered to be $200 \mathrm{mg} / \mathrm{kg} /$ day based on the mortality at 800 $\mathrm{mg} / \mathrm{kg} /$ day, decreases of gestation and mating indexes, and implantation loss rates at 400 and $800 \mathrm{mg} / \mathrm{kg} /$ day. In addition, the NOAEL for pups was considered to be $400 \mathrm{mg} / \mathrm{kg} /$ day based on a decrease of pups' body weights at $800 \mathrm{mg} /$ $\mathrm{kg} /$ day.

\section{ACKNOWLEDGMENTS}

This study was performed in 2014 at the Biotoxtech Co., Ltd. (Korea) and supported by the National Institute of Environmental Research, Republic of Korea.

\section{REFERENCES}

1. LookChem. Monoethyl Adipate. Available from: http://www. lookchem.com/Monoethyl-Adipate/.

2. OECD Existing Chemical Database. Ethyl hydrogen adipate.
Available from: http://webnet.oecd.org/hpv/ui/SponsoredSubstances.aspx/.

3. OECD (1995) OECD Test Guideline for Testing Chemicals, No. 421, Reproduction/Developmental Toxicity Screening Test. Adopted by the Council on 27th July 1995. Paris.

4. OECD (1998) OECD Principles on Good Laboratory Practice (as revised in 1997). OECD Series on Good Laboratory Practice and Compliance Monitoring, No. 1. Paris.

5. ChemIDPlus (A Toxnet Database). Adipic acid monoethyl ester. Available from: http://chem.sis.nlm.nih.gov/chemidplus/ $\mathrm{rn} / 626-86-8 /$.

6. Damsch, S., Eichenbaum, G., Tonelli, A., Lammens, L., Van den Bulck, K., Feyen, B., Vandenberghe, J., Megens, A., Knight, E. and Kelley, M. (2011) Gavage-related reflux in rats: identification, pathogenesis, and toxicological implications (review). Toxicol. Pathol., 39, 348-360.

7. Singh, A.R., Lawrence, W.H. and Autian, J. (1973) Embryonic-fetal toxicity and teratogenic effects of adipic acid esters in rats. J. Pharm. Sci., 62, 1596-1600.

8. Ronald, D.H. (2006) Developmental and reproductive toxicology: a practical approach (2nd edition), CRC Press, p. 442.

9. Sahota, P.S., Popp, J.A. and Hardisty, J.F. (2013) Toxicologic Pathology. Nonclinical Safety Assessment, CRC Press, pp. 279-281. 